\title{
Maternal and perinatal Outcome with Vaginal Birth After Cesarean in Hebei Province of china: a cross- sectional study
}

\section{xiaoxiao wang}

The First Hospital of Heibei Medical University

\section{YingKui Zhang}

Hebei Women and Children's Health Center

Lu Jia

Hebei General Hospital

\section{Yue Yang}

First Hospital of shaijiazhuang

Li Wang ( $\nabla$ wangli719@126.com )

\section{Research article}

Keywords: Vaginal birth after cesarean, Repeat cesarean section, Maternal outcome, Perinatal outcome, Vaginal delivery

Posted Date: January 21st, 2020

DOI: https://doi.org/10.21203/rs.2.21454/v1

License: (9) This work is licensed under a Creative Commons Attribution 4.0 International License. Read Full License 


\section{Abstract}

Background In recent decades, cesarean section rate have increased significantly in China. The delivery mode of women with a previous cesarean delivery remains contentious. We conducted a study to analyze the maternal and perinatal outcome of vaginal birth after cesarean or repeat cesarean delivery, in a period the one-child policy convert to the universal two-child policy.

Methods We used the data from Maternal Near Miss Surveillance System of Hebei province between 2013 and 2017. In the analysis, we included women with singleton deliveries between 28 and 42 gestation weeks who had a single prior cesarean delivery. We used logistic regression with a robust variance estimator to examine trends in vaginal birth after cesarean. We also assessed the association between vaginal birth after cesarean and maternal and perinatal adverse outcomes.

Results 53,769 women with a previous caesarean section deliveries were included from 274,665 of total participants. There were 3,415 (6.4\%) women delivered by vaginal birth after cesarean and 50,354 (93.6\%) by repeat cesarean delivery. Between 2013 and 2016, the rate of vaginal birth after cesarean showed a upward trend, from $6.2 \%$ to $7.0 \%$. But in 2017 , it had declined to $5.2 \%$. Compared to women with repeat cesarean delivery, women with vaginal birth after cesarean have lower absolute rates of severe maternal morbidity and mortality, especially significantly in incidence of blood transfusion, but have higher incidence of intrapartum stillbirth, newborns with low 5-minute Apgar score less than 7 and neonatal death.

Conclusions Most of maternal adverse outcomes risk of vaginal birth after cesarean was not higher than repeat cesarean delivery, but the risk of perinatal adverse outcomes has increased in vaginal birth after cesarean.

\section{Background}

As one of the main obstetrical operations, cesarean section is a remedial method for those who can not be delivered through vagina. With the improvement of surgical and anesthesia technology, the cesarean section has been considered a safe delivery and become a common mode of delivery in clinical practice $^{1,2}$.

The rates of cesarean section delivery was increasing worldwide, and there was some worry about this trend because of potential maternal and prenatal risks. The rates of caesarean section in China increased in the 1990 s $^{3,4}$. A survey of Asian countries in 2010 showed that China had the highest caesarean section rates ${ }^{4,5,6}$, which prompted the Chinese government to establish several policies to reduce it. With the universal two-child policy carried out since 2016, multiparous have increased, including those delivered with cesarean section in the first time ${ }^{7,8}$.

It was not an absolute solution for all pregnant women with a history of cesarean section to have another repeat cesarean section. Studies have shown that caesarean section can save maternal, fetal and 
neonatal life, but excessive use of caesarean section was a threat to a short-term and long-term maternal and child health, such as increased incidence of postpartum hemorrhage, organ damage ${ }^{9,10,11}$. At the same time, in order to reduce the rates of cesarean section and maternal and prenatal adverse outcomes, the vaginal birth after cesarean section (VBAC) was promoted worldwide, with the risk of uterine rupture threaten to the safety of mothers and babies ${ }^{12,13}$. whether the second delivery after cesarean section would be through vagina, this issue has been highly valued by obstetricians, but there is still a lack of large-scale research in this field. This study retrospectively analyzed the clinical data of 53,769 pregnant women who gave birth again after cesarean section in Hebei Province from January 2013 to December 2017. We compare the maternal and perinatal outcomes between VBAC and repeat caesarean delivery(RCD), to identify whether VBAC was a safe delivery mode.

\section{Methods}

\section{Data sources}

The data between January 2013 to December 2017 from Hebei Maternal Near Miss Surveillance System (HBMNMSS) was collected. There were 22 hospitals in 15 counties in Hebei province. The maternal deaths and near miss conditions were enumerated in women with severe complication of pregnancy or delivery, using the same approach suggested in the World Health Organization's global survey on maternal and perinatal health ${ }^{4}$. It covers different levels of hospitals (levels 1 to 3 , based on the number of beds, categories of clinical departments, numbers of medical personnel, type and quantity of equipment and hospital funding, where level- 1 consist of the smallest hospitals and level- 3 the largest ${ }^{14}$, with more than 1000 deliveries every year. In this study, we collected the deliveries information from the hospitals by the Survey Questionnaire form, which was designed by the China's National Maternal Near Miss Surveillance System. The information included Maternal age, Gestational age, Number of abortions, Education level, gravidity and parity, Hypertension, Diabetes mellitus, Length of hospital stay. Sampling strategy, data collection and reporting processes and quality control method of HBMNMSS have been detailed elsewhere, so as to avoid missed reports of hospitalized cases ${ }^{15,16}$.

We included only singleton pregnant women with one previous caesarean section and who delivered at 28 completed weeks of gestation or above. We excluded twin pregnancy. We classified maternal age into five subgroups, and common definitions for marital status and education as detailed elsewhere ${ }^{17}$. We extracted the day of the week from the date of delivery.

\section{Statistical analyses}

We used $\chi 2$ test to assess the trends in vaginal delivery after caesarean section by maternal age and hospital level. We also calculated the trends in the weighted rates of vaginal delivery after caesarean section in each subgroup. To examine the association between year and the rates of vaginal delivery after 
caesarean section, we used Logistic regression with a robust variance estimator, analyzing rare events, and binomial data on individuals. We used SPSS version 19.0 for our analyses, investigated both multicollinearity and model goodness-of-fit to identify the most robust and stable model.

We used a likelihood ratio test to obtain the $P$-value for the interaction among the variables by comparing models with and without interaction variables. Lastly, we compared the proportions of maternal and neonatal outcomes between vaginal delivery after caesarean section and RCD. We calculated the CRR and aRR for the following maternal outcomes: uterine rupture, blood transfusion, hysterectomy, intensive care unit admission, puerperal infection and mortality before discharge; and perinatal outcomes: intrapartum stillbirths, 5-minute Apgar score lower than 7 and neonatal death before discharge. We restricted the sample to deliveries without antepartum stillbirths for intrapartum stillbirths, to live births for 5-minute Apgar score lower than 7, and neonatal deaths before discharge. We defined uterine rupture as uterine or Lower uterine segment dehiscence in late pregnancy or during delivery, including complete and incomplete rupture.

\section{Results}

There were 274,665 women included in this study, aged 15 to 49 years, between 2013 and 2017. There were 53,769 women with previous cesarean delivery once, and who had a singleton delivery at 28 to 42 weeks gestation in the current pregnancy (Fig. 1).

Of these women, 22,268 (41.4\%) were 25 to 29 years of age, 2,858(5.3\%) had hypertension, 2,826(5.3\%) had diabetes mellitus. Women who had a RCD were older, and had higher rates of hypertension and diabetes mellitus than women who delivered after an VBAC (Table 1). The VBAC rates was $6.2 \%$ $(454 / 7,298)$ in 2013 , increased to $7.0 \%(993 / 14,227)$ in 2016 , decreased to $5.3 \%(766 / 14,389)$ in 2017. The proportion of women who delivered in level-2 hospitals were stable over the study period and the rates were about $71.2 \%$. And it was consistent with an increase in vaginal delivery rates, from $5.5 \%$ in 2013 to $7.1 \%$ in 2016, decreased to $5.8 \%$ in 2017, (Table 2). Table 3 shows rates of severe maternal morbidity and mortality after RCD and VBAC in the study population. Women who had an VBAC had significantly higher rates of intrapartum stillbirths, newborns with a 5-minute Apgar score less than 7 and neonatal death compared to women who had an RCD. 
Table 1

Maternal characteristics and mode of delivery ${ }^{a} n(\%)$

\begin{tabular}{|c|c|c|c|}
\hline & $\begin{array}{l}\text { VBAC } \\
N=3,415\end{array}$ & $\begin{array}{l}\text { RCD } \\
N=50,354\end{array}$ & P-value \\
\hline \multicolumn{4}{|l|}{ Maternal age, † (years) } \\
\hline$<20$ & $16(0.5)$ & $82(0.3)$ & \multirow[t]{5}{*}{$\varangle 0.001$} \\
\hline $20-24$ & 331(9.7) & $3,356(6.7)$ & \\
\hline $25-29$ & $1,481(43.4)$ & $20,782(41.3)$ & \\
\hline $30-34$ & $1,089(32.2)$ & 18,017(35.8) & \\
\hline$\geq 35$ & $489(14.3)$ & $8,112(16.1)$ & \\
\hline Gestational age(weeks) & $37.97 \pm 2.78$ & $38.40 \pm 1.38$ & $\varangle 0.001$ \\
\hline \multicolumn{4}{|l|}{ Number of abortions } \\
\hline$\bigotimes 3$ & $3,281(96.2)$ & $48,247(95.9)$ & \multirow[t]{2}{*}{0.34} \\
\hline$\geq 3$ & $129(3.8)$ & $2,073(4.1)$ & \\
\hline \multicolumn{4}{|l|}{ Education level } \\
\hline Primary & $1,587(46.5)$ & $21,024(41.8)$ & \multirow[t]{3}{*}{$凶 0.001$} \\
\hline Medium & $1,042(30.5)$ & $17,067(33.9)$ & \\
\hline High & $786(23.0)$ & $12,263(24.4)$ & \\
\hline Hypertension & $157(4.6)$ & $2,701(5.7)$ & 0.05 \\
\hline Diabetes mellitus & $145(4.2)$ & $2,681(5.3)$ & \\
\hline Length of hospital stay & $4.94 \pm 2.64$ & $6.25 \pm 2.60$ & $\varangle 0.001$ \\
\hline \multicolumn{4}{|c|}{ Note: $\mathrm{VBAC}=$ vaginal birth after cesarean; RCD = repeat cesarean delivery. } \\
\hline \multicolumn{4}{|c|}{$\begin{array}{l}\text { a We obtained data from } 22 \text { hospitals. Our study was restricted to women with a parity of } 1 \text { who had } \\
\text { a previous cesarean delivery and who delivered a singleton at } 28 \text { to } 42 \text { weeks gestation in the current } \\
\text { pregnancy in Hebei provinces (excluding Langfang) from } 2013 \text { to } 2017 \text {. Participants with missing } \\
\text { values were excluded. }\end{array}$} \\
\hline \multicolumn{4}{|c|}{$\begin{array}{l}\text { tFor maternal age, the denominators used were } 53,769 \text { (no. of participants with a previous cesarean } \\
\text { delivery), } 50,354 \text { (no. of participants with an repeat cesarean) and } 3,415 \text { (no. of participants with an } \\
\text { VBAC). }\end{array}$} \\
\hline
\end{tabular}


Table 2

Weighted rates of vaginal delivery after caesarean section, by maternal age and hospital level in Hebei, 2013-2017

\begin{tabular}{|c|c|c|c|c|c|}
\hline & \multicolumn{5}{|c|}{$\operatorname{VBAC} n(\%)^{a}$} \\
\hline & 2013 & 2014 & 2015 & 2016 & 2017 \\
\hline All deliveries & $454(6.2)$ & $693(6.7)$ & $509(6.8)$ & $993(7.0)$ & $766(5.3)$ \\
\hline \multicolumn{6}{|c|}{ Maternal age, $†$ (years) } \\
\hline$<20$ & $2(14.3)$ & $4(22.2)$ & $2(10.0)$ & $5(20.8)$ & $3(13.6)$ \\
\hline $20-24$ & $61(9.2)$ & $88(10.9)$ & $59(9.4)$ & 76(9.1) & $47(6.2)$ \\
\hline $25-29$ & $211(6.4)$ & $318(6.6)$ & $216(7.0)$ & $423(7.2)$ & $313(5.9)$ \\
\hline $30-34$ & $127(5.1)$ & 195(5.5) & $161(6.4)$ & $345(6.6)$ & $270(5.1)$ \\
\hline$\geq 35$ & $53(6.1)$ & $88(7.23)$ & $71(5.8)$ & $144(6.3)$ & $133(4.4)$ \\
\hline \multicolumn{6}{|l|}{ Hospital level } \\
\hline Level 1 & $31(5.7)$ & $29(4.3)$ & 16(3.5) & $41(4.0)$ & $24(2.7)$ \\
\hline Level 2 & $285(5.5)$ & $476(6.2)$ & $344(6.5)$ & $698(7.1)$ & $584(5.8)$ \\
\hline Level 3 & $138(8.9)$ & $188(9.1)$ & 149(8.8) & 254(7.6) & $158(4.7)$ \\
\hline \multicolumn{6}{|c|}{ † We used $\chi^{2}$-test to examine the distribution differences. } \\
\hline \multicolumn{6}{|c|}{$\begin{array}{l}\text { Notes: We obtained data from } 22 \text { hospitals. Our study was restricted to women with a parity of } 1 \text { who } \\
\text { had a previous cesarean delivery and who delivered a singleton at } 28 \text { to } 42 \text { weeks gestation in the } \\
\text { current pregnancy in Hebei provinces (excluding Langfang) from } 2013 \text { to } 2017 \text {. Participants with } \\
\text { missing values were excluded. Level-1 hospitals are the smallest hospitals, while level-3 hospitals are } \\
\text { the largest. }\end{array}$} \\
\hline \multicolumn{6}{|c|}{ Inconsistencies arise in some values due to rounding. } \\
\hline
\end{tabular}


Table 3

Comparison of maternal and perinatal outcome between vaginal birth after caesarean section and repeat caesarean delivery in Hebei, 2013-2017

\begin{tabular}{|c|c|c|c|c|}
\hline & \multicolumn{2}{|c|}{$\begin{array}{l}\text { Weighted rates (no. of } \\
\text { births) }{ }^{a}\end{array}$} & \multirow[t]{3}{*}{$\operatorname{cRR}(95 \% \mathrm{Cl})^{\mathrm{d}}$} & \multirow[t]{3}{*}{$\operatorname{aRR}(95 \% \mathrm{Cl})^{e}$} \\
\hline & VBAC $^{b}$ & $\mathrm{RCD}^{\mathrm{c}}$ & & \\
\hline & $n(\%)$ & $n(\%)$ & & \\
\hline \multicolumn{5}{|l|}{ Maternal Outcome } \\
\hline Uterine ruptures & $4(1.2)$ & $39(0.8)$ & $1.55(0.55-4.35)$ & $\begin{array}{l}1.08(0.37- \\
3.21)\end{array}$ \\
\hline Blood transfusion & $31(9.1)$ & $670(13.3)$ & $0.68(0.47-0.98)$ & $\begin{array}{l}0.36(0.25- \\
0.54)\end{array}$ \\
\hline Hysterectomies & $1(0.3)$ & $24(0.5)$ & $0.61(0.08-4.54)$ & $\begin{array}{l}0.18(0.02- \\
1.48)\end{array}$ \\
\hline ICU admissions & $2(0.6)$ & $25(0.5)$ & $1.18(0.28-4.98)$ & $\begin{array}{l}0.51(0.11- \\
2.31)\end{array}$ \\
\hline Puerperal infection & $1(0.3)$ & $7(0.1)$ & $2.11(0.26-17.13)$ & $\begin{array}{l}1.49(0.17- \\
12.37)\end{array}$ \\
\hline $\begin{array}{l}\text { Maternal mortality before } \\
\text { discharge }\end{array}$ & $1(29.3)$ & $1(2.0)$ & $0.07(0.00-1.08)$ & $0.18(0.01-5.00)$ \\
\hline \multicolumn{5}{|l|}{ Perinatal Outcome } \\
\hline Intrapartum stillbirths & $44(12.9)$ & $29(0.6)$ & $\begin{array}{l}23.76(14.85- \\
38.02)\end{array}$ & $\begin{array}{l}9.83(5.48- \\
17.64)\end{array}$ \\
\hline 5-minute Apgar scores $<7$ & $22(6.4)$ & $97(1.9)$ & $3.65(2.29-5.81)$ & $\begin{array}{l}2.19(1.31- \\
3.67)\end{array}$ \\
\hline $\begin{array}{l}\text { Neonatal deaths before } \\
\text { discharge }\end{array}$ & $11(3.2)$ & $43(0.9)$ & $0.25(0.12-0.50)$ & $\begin{array}{l}0.45(0.21- \\
0.98)\end{array}$ \\
\hline \multicolumn{5}{|c|}{$\begin{array}{l}\text { aRR: adjusted relative ratio; } \mathrm{Cl} \text { : confidence interval; cRR: crude relative ratio; ICU: intensive care unit; } \\
\text { VBAC: vaginal birth after cesarean; } \mathrm{RCD} \text { :repeat cesarean delivery. }\end{array}$} \\
\hline \multicolumn{5}{|c|}{$\mathrm{n}(\% \mathrm{o})=$ number per 1,000 births(proportion, \%o) } \\
\hline \multicolumn{5}{|c|}{ a No. of births represents all births if not indicated live births. } \\
\hline \multicolumn{5}{|c|}{ b The sample for vaginal birth after caesarean section were 3,415 births and 3,198 live births. } \\
\hline
\end{tabular}




\section{Weighted rates (no. of \\ $\operatorname{cRR}(95 \% \mathrm{Cl})^{\mathrm{d}}$ \\ $\operatorname{aRR}(95 \% \mathrm{Cl})^{\mathrm{e}}$ \\ births) $)^{a}$}

$\begin{array}{ll}\text { VBAC }^{b} & \text { RCD }^{c} \\ n(\% \circ) & n(\% \circ)\end{array}$

${ }^{d}$ We weighted the rates for sampling distribution of population and adjustment for clustering of births within hospitals.

e We adjusted the cRR for year, hospital level, level of education, maternal age, diabetes mellitus, hypertension, gestational age and birth weight.

${ }^{f}$ Information about perinatal outcome was missing from 369 (0.69\%) births. We excluded 14 (0.03\%) antepartum stillbirths from the total number of births.

g We restricted the analysis to live births.

\section{Discussion}

Our study showed that the rates of VBAC rates increased during the relaxation of the one-child policy. We found increasing trends for women older than 25 years, for women with one previous caesarean section and in level- 2 hospitals. The absolute rates of severe maternal morbidity and mortality were low among women who had a VBAC and those who had a RCD. However, relative rates of serious neonatal morbidity and mortality were substantially higher in VBAC. Between 2013 and 2016, the proportion of pregnant women with a previous caesarean section in Hebei province increased from $13.8 \%(7,333 / 52,968)$ to $22.5 \%(14245 / 63218)$, and reached $26.3 \%(14,416 / 54,715)$ by 2017 , which was higher than the average level of China ${ }^{18}$. This could be explained by the large number of women with a previous caesarean section and the increase in number of women wanting to have a second child after universal two-child policy $^{18}$. In $2017,54.7 \%(29,945 / 54,715)$ of participants were multiparas. It suggested that the RCD rates would increase in China after years of high cesarean section rate, if VBAC were not taken. Studies from several countries also have shown that VBAC is an elective measure for reducing RCD rates ${ }^{19,20,21}$. Despite the debate in China whether to support VBAC as a measure to reduce the caesarean section rates $^{22,23,24}$, some hospitals have encouraged trial of labour after caesarean section since $2010^{17,25}$. This promotion of VBAC has been done to achieve reduction in the caesarean section rates and to act as maternal requirements with a prior caesarean section. Surprisingly, we found that the rate of VABC in level-2 hospitals was higher than that in level-3 hospitals. Considered that it may be related to referral of pregnant and lying-in women with complications in lower-level hospitals. The change of population policy to universal two-child policy shows an opportunity to promote VBAC in China. But to ensure the safety of mothers and their newborns, we mostly choose to have another cesarean section. So it's clear that the VBAC rates in level-2 hospitals increased from 5.5-7.1\%, but declined to $5.8 \%$ by 2017 . Compared with developed country, the VBAC rates in China seems to have a potential to further increase $26,27,28$. 
However, women in China with a previous caesarean section still have limited choices for a preferred delivery mode. In general, it appears that clinicians easily opt for repeat CS. Most obstetricians worried about been sued for adverse outcomes and bear the loss of income, so they may be reluctant to implement VBAC in their wards ${ }^{29,30}$, with the risk of uterine rupture, operative injury, fetal or neonatal death $^{31,32}$. In our study, the maternal morbidity and mortality of VBAC was very low, such as $1.2 \%$ o of uterine rupture, which was in contrast to other studies $(16.8 \%)^{33}$. It suggested that VBAC was a safe mode of delivery, if master the indications and observe closely.

A cohort study in the UK also confirmed that the complications was reduced by vaginal compression of the fetus, such as wet lung and respiratory distress syndrome that caused by excessive retention of pulmonary fluid, and long-term asthma of newborns delivered by elective cesarean section was significantly increased (HR: $1.24,95 \% \mathrm{Cl}: 1.09-1.42){ }^{34}$. Therefore, it is very necessary to have a trial of labor after cesarean(TOLAC), as Young ${ }^{31}$. There were higher rates of perinatal adverse outcomes in women with VBAC than who with RCD. We found a significant increase in the rate of intrapartum stillbirths among the infants of women who underwent VBAC $(12.9 \%$ o) as compared with infants born after $\operatorname{RCD}(0.6 \%)$. It was necessary that neonatologists involve to the process of trial of labour after caesarean section, to ensure the timely treatment for perinatal adverse outcomes ${ }^{14}$.

Strengths and limitations: The HBMNMSS was a well established surveillance system with rigorous quality controls, involved 22 hospitals, covering a large sample, the results still have value for the choice of delivery mode. But we could not obtain the information of women undergoing TOLAC and failed, no information of VBAC after elective cesarean section or emergency cesarean section, it might be a bias in outcomes of VBAC.

\section{Conclusion}

Most of maternal adverse outcomes risk of VBAC was not higher than RCD, but the risk of perinatal adverse outcomes has increased in VBAC. Strategies must take to reduce the perinatal risk, and to reduce primary caesarean section. At the same time, health care providers need to help women to understand delivery mode better, so they can make personalized decisions.

\section{Declarations}

\section{Abbreviations}

TOLAC: Trial of labor after cesarean; VBAC: Vaginal birth after cesarean; RCD: repeat caesarean delivery; WHO: World health organization; ICU: Intensive Care Unit; HBMNMSS: Hebei Maternal Near Miss Surveillance System.

\section{Acknowledgments}


Thank you to the staff of Hebei Women and Children's Health Center for data collection.

\section{Funding}

No funding received for this study.

\section{Availability of data and materials}

The datasets used and analyzed in the current study are available from the corresponding author on reasonable request.

\section{Authors' contributions}

All authors have contributed to the design of this study. YKZ were responsible for data gathering, and data analysis was performed by XXW. Manuscript was drafted by XXW. XXW, YY, LJ and LW contributed in the study design, reviewing the data and writing the manuscript. All authors have contributed in the revision of the study and gave approval of the final version of the manuscript.

\section{Ethics approval and consent to participate}

Ethical clearance was obtained from Hebei Women and Children's Health Center (20171029-1).

Participants were verbally consented to be interviewed and recorded. Written consent was waived by the Ethics Committee given the low-risk nature of the research and anonymity of all interviews.

\section{Consent for publication}

Not applicable.

\section{Competing interests}

The authors declare that they have no competing interests.

\section{Publisher's Note}


Springer Nature remains neutral with regard to jurisdictional claims in published maps and institutional affiliations.

\section{Author details}

1. Department of Obstetrics and Gynecology, Hebei General Hospital, Shijiazhuang 050051,China

2. Department of Obstetrics and Gynecology, The First Hospital of Hebei Medical University, Shijiazhuang 050031, China

3. Hebei Women and Children's Health Center, No. 147 Jianhua Street, Shijiazhuang, 050000, China

4. First Hospital of Shijiazhuang, Shijiazhuang Hebei 050011,China

\section{References}

1. Li H-T , Luo S , Trasande L , et al. Geographic Variations and Temporal Trends in Cesarean Delivery Rates in China, 2008-2014[J]. JAMA, 2017, 317(1):69.

2. Zhang J, Liu Y, Meikle S, et al. Cesarean delivery on maternal request in southeast China[J]. Obstetrics \& Gynecology, 2008, 111(5): 1077-1082.

3. Liu L, Feng X-F and Yi G-Y. Changes in Cesarean Section Rate and Indications and Perinatal Delivery in the Past 10 Years [J]. Chinese Journal of Practical Gynecology and Obstetrics, 2003, 19 (1): 43-44.

4. Lumbiganon P, Laopaiboon M, Gülmezoglu AM, et al. Method of delivery and pregnancy outcomes in Asia: the WHO global survey on maternal and perinatal health 2007ه2008. Lancet, 2010, 375( 9713) : 490-499.

5. Hellerstein S, Feldman S, Duan T. China's 50\% caesarean delivery rate: is it too high? BJOG. 2014;122:160-4.

6. Feng $\mathrm{X}-\mathrm{L}, \mathrm{Xu} \mathrm{L}$, Guo $\mathrm{Y}$, Ronsmans $\mathrm{C}$. Factors influencing rising caesarean section rates in China between 1988 and 2008. Bull World Health Organ.2012;90:30-9A.

7. Liu Y, Li G, Chen Y, Wang X, Ruan Y, Zou L, et al. A descriptive analysis of the indications for caesarean section in mainland China. BMC Pregnancy Childbirth. 2014;14:410.

8. Zeng Y, Hesketh T. The effects of China's universal two-child policy[J]. The Lancet, 2016, 388(10054): 1930-1938.

9. Sandall J, Tribe R M, Avery L, et al. Short-term and long-term effects of caesarean section on the health of women and children[J]. The Lancet, 2018, 392(10155): 1349-1357.

10. Nuamah M A, Browne J L, Alexander V, et al. Prevalence of adhesions and associated postoperative complications after cesarean section in Ghana: a prospective cohort study[J]. Reproductive Health, 2017, 14(1):143. 
11. Dodd JM, Crowther CA, Grivell RM, et al. Elective repeat cesarean section versus induction of labour for women with a previous cesarean birth. Cochrane Database Syst Rev 2014;(12):CD004906.

12. Beucher $G$, Dolley $P$, LévyThissier $S$, et al. [Maternal benefits and risks of trial of labor versus elective repeat caesarean delivery in women with a previous caesarean delivery].[J]. J Gynecol Obstet Biol Reprod, 2012, 41(8):708-726.

13. Marshall N E, Fu R, Guise J M. Impact of multiple cesarean deliveries on maternal morbidity: a systematic review[J]. American journal of obstetrics and gynecology, 2011, 205(3): 262. e1-262. e8.

14. Liang J, Mu Y, Li X, Tang W, Wang Y, Liu Z, et al. Relaxation of the one child policy and trends in caesarean section rates and birth outcomes in China between 2012 and 2016: observational study of nearly seven million health facility births. BMJ. 201803 5;360:k817.

15. Zhu J, Liang J, Mu Y, Li X, Guo S, Scherpbier R, et al. Sociodemographic and obstetric characteristics of stillbirths in China: a census of nearly 4 million health facility births between 2012 and 2014. Lancet Glob Health. 2016 Feb;4(2):e109-18.

16. [The measures for the administration of the hospital grade]. Beijing: Ministry of Health of China; 1989.

17. Mu Y , Li X, Zhu J , et al. Prior caesarean section and likelihood of vaginal birth, 2012-2016, China[J]. Bulletin of the World Health Organization, 2018, 96(8):548-557.

18. Ming Y , Li M , Dai F , et al. Dissecting the current caesarean section rate in Shanghai, China[J]. Scientific Reports, 2019, 9(1).

19. Sabol B, Denman MA, Guise JM. Vaginal birth after cesarean: an effective method to reduce cesarean. Clin Obstet Gynecol. 2015 Jun;58(2):309-19.

20. Sakiyeva KZ, Abdelazim IA, Farghali M, et al.Outcome of the vaginal birth after cesarean section during the second birth order in West Kazakhstan. J Family Med Prim Care. 2018 Nov-Dec; 7(6): 1542-1547.

21. Moeed, Saman M . Improving VBAC rates: the combined impact of two management strategies[J]. Australian and New Zealand Journal of Obstetrics and Gynaecology, 2014, 54(6):601-602.

22. Ma RM, Duan T, Lao TT. VBAC should be encouraged as a means to reduce the caesarean section rate in China: FOR: VBAC reduces not only the caesarean section rate but also other associated issues. BJOG. 2016.

23. Yang H-X, Li B-Y. Challenges in the Post-cesarean Era: Pregnancy after Cesarean Section Problems related to vaginal delivery [J]. Chinese Journal of Obstetrics and Gynecology, 2016,51 (8): 573-575.

24. Socol M L , Garcia P M , Peaceman A M , et al. Reducing cesarean births at a primarily private university hospital[J]. American Journal of Obstetrics and Gynecology, 1993, 168(6):1748-1758.

25. Wang E, Hesketh T. Large reductions in cesarean delivery rates in China: a qualitative study on delivery decision-making in the era of the two-child policy[J]. BMC pregnancy and childbirth, 2017, 17(1): 405. 
26. Menacker F, Curtin SC. Trends in cesarean birth and vaginal birth after previous cesarean, 1991-99. Natl Vital Stat Rep. 2001 Dec 27;49(13):1-16.

27. Millar WJ, Nair C, Wadhera S. Declining cesarean section rates: a continuing trend? Health Rep. 1996 Summer;8(1):17-24, 17-24 (Fre).

28. Perinatal health report: deliveries in British Columbia 2014/15. Vancouver: Perinatal Services BC; 2016. Available: www.perinatalservicesbc.ca/Documents/ DataSurveillance/Reports/PHR/PHR_BC_2014_15.pdf (accessed 2017 Nov 20).

29. Ji H, Jiang H, Yang L, Qian X, Tang S. Factors contributing to the rapid rise of caesarean section: a prospective study of primiparous Chinese women in shanghai. BMJ Open. 2015;5:e008994.

30. Deng W, Klemetti R, Long Q, Wu Z, Duan C, Zhang W-H, et al. Cesarean section in shanghai: women's or healthcare provider's preferences? BMC Pregnancy Childbirth. 2014;14:285.

31. Young C-B, Liu S, Muraca G M, et al. Mode of delivery after a previous cesarean birth, and associated maternal and neonatal morbidity[J]. Cmaj, 2018, 190(18): E556-E564.

32. Yang Y-Z, Ye X P, Sun X-X. Maternal and neonatal morbidity: repeat Cesarean versus a trial of labour after previous Cesarean delivery[J]. Clinical and Investigative Medicine, 2017: E135-E145.

33. Kalisa R, Rulisa S , Van Roosmalen J , et al. Maternal and perinatal outcome after previous caesarean section in rural Rwanda[J]. BMC Pregnancy and Childbirth, 2017, 17(1):272.

34. Mairead B , Siladitya B , Sam P, et al. Planned Repeat Cesarean Section at Term and Adverse Childhood Health Outcomes: A Record-Linkage Study[J]. PLOS Medicine, 2016, 13(3):e1001973.

\section{Figures}




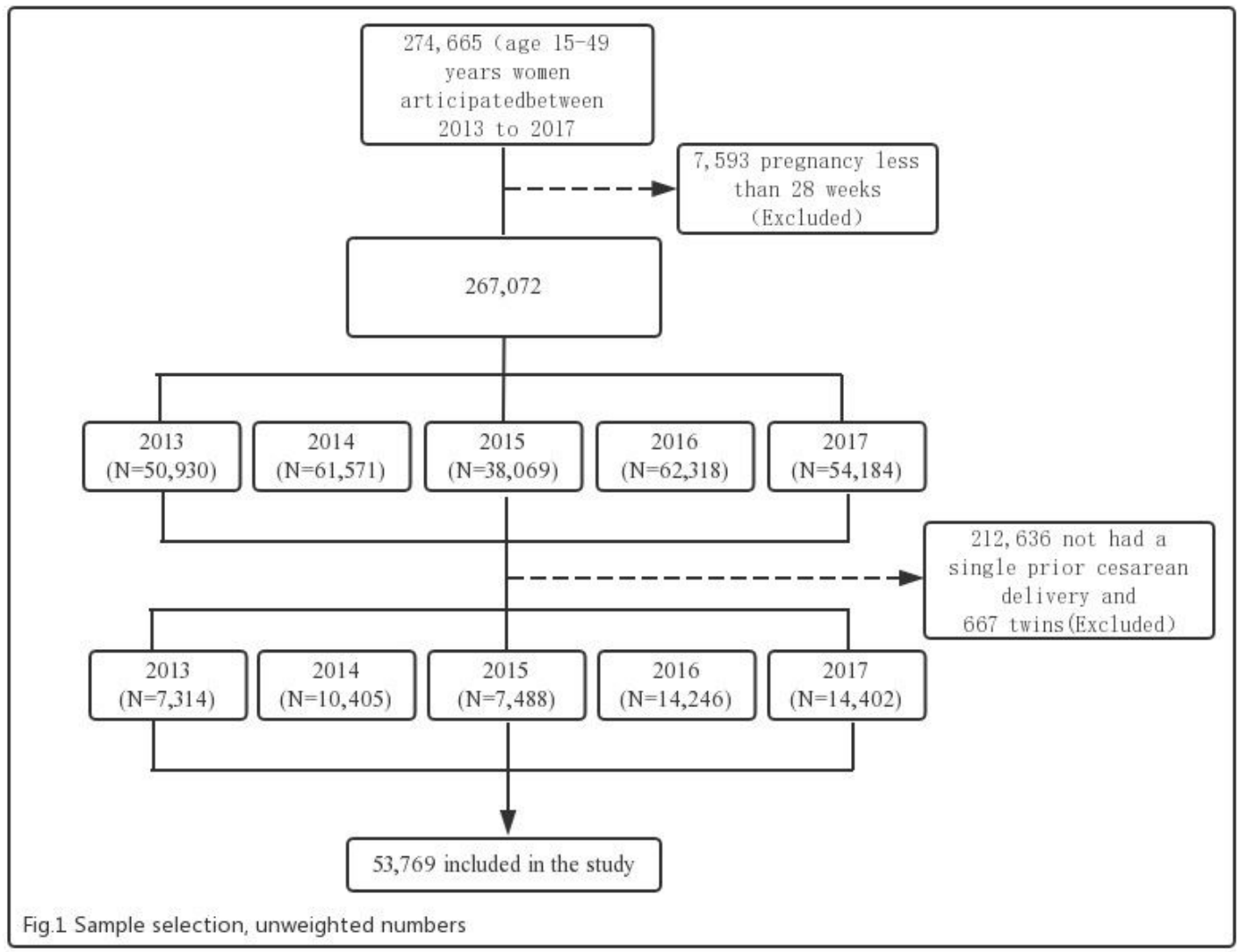

Figure 1

Sample selection, unweighted numbers

\section{Supplementary Files}

This is a list of supplementary files associated with this preprint. Click to download.

- STROBEchecklistcrosssectional.pdf 